\title{
The Advantage Of Hyaluronidase In Rectus Sheath Block For Pain Control In Laparoscopic Cholecystectomy
}

\author{
Fatma Mohamed Abdelaziz ${ }^{1, *}$ MD, Rasha Abd Elaziz Abd Elghany ${ }^{2}$ MD.
}

* Corresponding Author:

Fatma Mohamed Abdelaziz

fatmamohamed.medg@azhar.edu.eg

Received for publication July 12, 2021; Accepted August 22, 2021;

Published online August 22, 2021.

Copyright The Authors
published by Al-Azhar
University, Faculty of Medicine,
Cairo, Egypt. Users have the
right to read, download, copy,
distribute, print, search, or link
to the full texts of articles under
the following conditions:
Creative Commons Attribution-
Share Alike 4.0 International
Public License (CC BY-SA 4.0).
doi: 10.21608/aimj.2021.85801.1525
${ }^{1}$ Anesthesia and Intensive care
Department, Faculty of Medicine
(for Girls), Al-Azhar University,
Cairo, Egypt.
${ }^{2}$ general surgery Department,
Faculty of Medicine (for Girls),
Al-Azhar University, Cairo, Egypt.

\begin{abstract}
Background: Rectus sheath block (RSB) had been proven to reduce the pain associated with ventral abdominal surgical incisions and laparoscopic surgery. We hypothesized that the addition of hyaluronidase could increase the effectiveness of the (RSB) technique by improving the local anesthetic (LA) spread.

Aim of the study: : Effectiveness of adding the hyaluronidase as an adjuvant to bupivacaine in ultrasound-guided rectus sheath block (RSB) in those patients planning for laparoscopic cholecystectomy (LC).

Patients and Methods: Eighty patients, their ages ranged from 20-60 years old, ASA physical status I to II, and undergoing elective (LC): were assigned in this study and allocated randomly into two equal groups. Group $(\mathrm{H})$ had given preoperative rectus sheath block with $19 \mathrm{ml}$ of bupivacaine $0.25 \%+1 \mathrm{ml}$ of hyaluronate $1500 \mathrm{IU}$, and control group (B) received preoperative rectus sheath block $19 \mathrm{ml}$ of bupivacaine $0.25 \%+1 \mathrm{ml}$ of normal saline on each side after standardized induction sequence.

Results: mean intraoperative fentanyl consumption exhibited a significant decline in Group H $(167.75 \pm 20.6)$ ug compared to Group B $(186.25 \pm 20.57)$ ug $p<0.001$. Numerical Rating Score (NRS) was significantly less in the $\mathrm{H}$ group than in the B group at $0,1,2,4,6$ hours postoperatively with A significant $\mathrm{p}$-value. There was a significant decrease in the total dose of pethedine in $24 \mathrm{hrs}(\mathrm{P}<0.001)$ in Group $\mathrm{H}$ (55.75 \pm 14.66$) \mathrm{mg}$ compared to Group B $(82.50 \pm 36.57) \mathrm{mg}$.

Conclusion: Preoperative RSB by adding hyaluronidase to bupivacaine reduced the need for analgesia during the intraoperative time and 24 hours postoperatively in patients planning for LC, versus the preoperative RSB without hyaluronidase.
\end{abstract}

Keywords: Pain control, Rectus sheath block, Hyaluronidase.

Disclosure: The authors have no financial interest to declare in relation to the content of this article. The Article Processing Charge was paid for by the authors.

Research Support: RCT approval numbers: NCT04656067 and PACTR202101794541918

Authorship: All authors have a substantial contribution to the article.

\section{INTRODUCTION}

Laparoscopic cholecystectomy (LC) is one of the most common elective surgical operations as it is less invasive and has less postoperative pain in comparison to open cholecystectomy ${ }^{1}, 2$.

The post laparoscopic cholecystectomy pain is multifactorial and has multiple origins like trocar site pain, visceral pain, and referred shoulder pain due to the pneumoperitoneum. The largest component is the trocar sites pain $(50-70 \%)$, which is usually moderate in severity, and maximal immediately postoperatively ${ }^{1,3}$.

The intensity of the pain following LC suggests that multimodal analgesia could be indicated. The pain management by opioids alone is associated with adverse events such as nausea, vomiting, and respiratory depression leading to delayed discharge.
Therefore, the associated regional analgesic techniques for the anterior abdominal wall are an excellent choice for laparoscopic procedures ${ }^{3}, 4$.

In 1899 Schleich described the rectal sheath block to help relax the anterior abdominal wall. RSB provides analgesia from the xiphisternum to the symphysis pubis over the central area of the anterior abdominal wall. The RSB is part of multimodal pain analgesia as it relieves the somatic pain in the abdominal wall layers anterior to the peritoneum and is mainly effective in incisional pain ${ }^{5}$.

The RSB provides analgesia by blocking ventral branches of the T9-T11 nerve roots; which lie between the rectus abdominis muscle and the posterior layer of the rectus sheath till entering the rectus muscle near the midline ${ }^{6}$. 
Many adjuvant drugs have been added to local anesthetic drugs to acquire a quick, powerful, and extended regional block. We conducted this study to determine the advantage of adding hyaluronidase with local anesthetic agents in the rectus sheath block for LC operation as part of multimodule analgesia regarding the intraoperative fentanyl consumption, for pain numerical rating score (NRS) and total dose of analgesia in 24 hours.

\section{Sample size justification:}

MedCalc $\AA$ version 12.3.0.0 program "Ostend, Belgium" was used for calculations of sample size, statistical calculator based on $95 \%$ confidence interval and power of the study $80 \%$ with $\alpha$ error $5 \%$, According to a previous study (Ibrahim et al, 2016), showed that Intraoperative rescue fentanyl in RSB Group was $12.85 \pm 3.65$ ug compared to control Group was $19.23 \pm 4.96 \mathrm{ug}$, with $\mathrm{p}$-value $<0.001$. So, it can be relied upon in this study, based on this assumption, sample size was calculated according to these values produced a minimal samples size of 80 cases were enough to find such a difference, subdivided into two groups 40 patients in each group. ${ }^{7}$

Methods of randomization: the randomization of patients was using a computerized program (SPSS), while sealed envelopes was numbered according to the randomization tables, than Packing, sealing and numbering of the envelope was performed by a neutral medical personnel (Under the supervision of doctors from the Department), the number of cases included in this study was simple randomly allocated into two groups.

\section{PATIENTS AND METHODS}

This is a prospective randomized clinical study that was carried out at

Al- Zahraa University Hospital between June 2020 to June 2021.

Eighty patients, their ages range from 20-60 years old of both sexes ASA physical statuses I to II planning for elective laparoscopic cholecystectomy. They were enrolled in this study and randomly allocated into two equivalent groups. Group $(\mathrm{H})$ were given preoperative rectus sheath block with $19 \mathrm{ml}$ of bupivacaine $0.25 \%+1 \mathrm{ml}$ of hyluronate $1500 \mathrm{IU}$, and control group (B) received preoperative rectus sheath block $19 \mathrm{ml}$ of bupivacaine $0.25 \%+1 \mathrm{ml}$ of normal saline on each side after standardized induction sequence.

Exclusion Criteria were patients with BMI >35, Chronic hepatic or renal disease, coagulation disorder, allergy to local anesthetics, chronic opioid consumption, sever psychiatric disorder, or conversion of laparoscopic to open surgery.

Outcomes: primary outcome of this study was intraoperative fentanyl consumption and secondary outcome was numerical rating score (NRS) for pain and analgesia in 24 hour postoperative.

Every patient was informed about the procedure and written informed consent was obtained.
Preoperative assessment of the patients included: detailed medical history, previous medication, complete physical examination, and routine investigations. Every patient was instructed about numerical rating score (NRS) where 0 no pain and 10 the worst pain.

Anesthetic Technique: All patients were fasting eight hours before surgery.

In preoperative preparation area a peripheral line was inserted in a peripheral vein. In the operative room, maintenance fluids were calculated. Standard monitoring was applied to the patient.

Pre-oxygenation for at least 3 minutes before induction of anesthesia then starting with fentanyl (1$2 \mathrm{mcg} / \mathrm{kg} \mathrm{IV}$ ) and propofol (1-2mg/ kg IV) until the response to verbal commands have been lost. Endotracheal intubation was enabled by a cisatracurium $0.15 \mathrm{mg} / \mathrm{kg}$. Then patients received sevoflurane $(1 \%$ $-2 \%)$.

Preoperative Rectus sheath block (RSB): The skin was disinfected. The rectus sheath block was performed on both sides of anterior abdominal wall with a 5-12 MHz high-frequency linear transducer (Sonosite M TURBO; FUJIFILM SonoSite Inc., USA). A $22 \mathrm{G}$ insulated needle was used via an inplane approach. A linear probe was placed transversely on the abdomen, just above the umbilicus. The needle was introduced between the rectus muscle and posterior fascia then the transducer was rotated to the longitudinal plane for visualization of the needle. The site of the needle was confirmed by aspiration and injection of $2 \mathrm{ml}$ saline $0.9 \%$ separation of rectus muscle from posterior fascia then local anesthetic was injected $20 \mathrm{ml}$ on each side $(19 \mathrm{ml}$ of bupivacaine $0.25 \%$ plus $1 \mathrm{ml}$ of hyluronate $1500 \mathrm{IU})$ in group $(\mathrm{H})$ and $(19 \mathrm{ml}$ of bupivacaine $0.25 \%+1 \mathrm{ml}$ of normal saline) in group (B). The rectus sheath block provides somatic pain relief by the block of 9th-11th anterior ramie intercostal nerves. It can be used for postoperative analgesia for ventral abdominal wall structures superficial to the peritoneum, but not for visceral pain.

Operative Technique: All operations were done in reverse Trendelenburg position with slight tilting to the left side. Pneumoperitoneum was installed through a veress needle then a supraumbilical trocar $(10 \mathrm{~mm})$ was inserted for camera port and visualization of the abdominal cavity. Another two trocars were inserted under vision, the first one $(10 \mathrm{~mm})$ below the xiphoid process, and $(5 \mathrm{~mm})$ trocar Below the right costal margin. Dissection was done at calot triangle for identification of cystic duct and artery and their clipping and dissection. Dissection of the gallbladder from its bed via monopolar electrocautery and its extraction via the epigastric port. In the case of difficult dissection or long gallbladder, a fourth trocar was added. An intraperitoneal drain was inserted for $24 \mathrm{hr}$ routinely.

Inspired volatile anesthetic concentration was modified to keep pulse and non invasive blood pressure (NIBP) within $20 \%$ of pre-anesthetic values. Controlled ventilation using a closed circle system 
with a total fresh gas flow rate of $3 \mathrm{~L} / \mathrm{min}$. acute changes in hemodynamics was controlled with further doses of fentanyl $(0.5-1.0 \mathrm{mcg} / \mathrm{kg}$ IV to the maximium dose of $150 \mathrm{mcg}$ ) and the total dose was recorded in each group. top-up doses of cisataracium $0.015 \mathrm{mg} / \mathrm{kg}$ were administered during anesthesia.

The inspired anesthetics were diminished to 0.5 MAC ten minutes before the approximate ending of the surgery. Infusion of paracetamol $15 \mathrm{mg} / \mathrm{kg}$ and ondansetron $4 \mathrm{mg}$ IV were administered to all participants. At the end of the operation, Sevoflurane was stopped, the lungs were ventilated with $100 \% \mathrm{O} 2$ at a fresh gas flow rate of $8 \mathrm{~L} / \mathrm{min}$. When signs of adequate recovery were observed, the remaining neuromuscular blockade was reversed using anticholinestrase (neostignine)and atropine.

In postoperative care unit (PACU) the patients were assessed by modified Aldrete recovery score $^{8}$ postoperatively, when the Score was $\geq 9$, the patients were discharged to the ward. At the time of arrival to PACU, Assessment of pain by Numerical Rating Score (NRS) then assessment was done at $1 \mathrm{hr}$., 2 hr.,4 hr.,6hr.,9hr.,18hr., $24 \mathrm{hr}$ postoperative. Intravenous pethidine $(0.5 \mathrm{mg} / \mathrm{kg})$ was given, when NRS was $>4$ or when the patient needed pain relief. the Total doses of pethidine given were recorded.

\section{Statistical analysis}

The recorded data were analyzed using the statistical package for social sciences, version 20.0 (SPSS Inc., Chicago, Illinois, USA). The Quantitative data were expressed as mean \pm standard deviation (SD) and Qualitative data were expressed as frequency and percentage. The following tests were done:

$\square$ Independent-samples t-test of significance was used when comparing between two means. $\square$ Mann Whitney U test: for two-group comparisons in nonparametric data. $\square$ Chi-square (x2) test of significance was used in order to compare proportions between qualitative parameters. $\square$ The confidence interval was set to $95 \%$ and the margin of error accepted was set to $5 \%$. So, the p-value was considered significant as the following:

Probability (P-value) P-value $<0.05$ was considered significant. , P-value $<0.001$ was considered as highly significant. ,P-value $>0.05$ was considered insignificant

\section{RESULTS}

Eighty patients undergoing LC were assigned in our study and divided into two equal groups randomly with, 40 patients in each group. Group $(\mathrm{H})$ has given preoperative rectus sheath block with $19 \mathrm{ml}$ of bupivacaine $0.25 \%+1 \mathrm{ml}$ of hyaluronidase $1500 \mathrm{IU}$, and control group (B) received preoperative rectus sheath block $19 \mathrm{ml}$ of bupivacaine $0.25 \%+1 \mathrm{ml}$ of normal saline on each side after standardized induction sequence.

There were no significant differences in both groups according to their baseline characteristics regards age, sex, ASA, and operative time as shown in (Table1).

\begin{tabular}{|c|c|c|c|c|}
\hline $\begin{array}{c}\text { Demographic } \\
\text { data }\end{array}$ & $\begin{array}{c}\text { Group B } \\
(\boldsymbol{n}=\mathbf{4 0})\end{array}$ & $\begin{array}{c}\text { Group } \\
\mathbf{H} \\
(\boldsymbol{n}=\mathbf{4 0})\end{array}$ & Test & $\begin{array}{c}\text { P } \\
\text { value }\end{array}$ \\
\hline $\begin{array}{c}\text { Age (years) } \\
\text { Mean } \pm \text { SD } \\
\text { Range }\end{array}$ & $\begin{array}{c}38.00 \pm 8.87 \\
24-59\end{array}$ & $\begin{array}{c}39.13 \pm 9.45 \\
23-60\end{array}$ & $\mathrm{t}=-0.549$ & 0.585 \\
\hline $\begin{array}{c}\text { Sex } \\
\text { Male }\end{array}$ & $\begin{array}{c}31(77.5 \%) \\
9(22.5 \%)\end{array}$ & $\begin{array}{c}28(70 \%) \\
12(30 \%)\end{array}$ & $\mathrm{x} 2=0.581$ & 0.446 \\
\hline $\begin{array}{c}\text { ASA } \\
\text { I }\end{array}$ & $\begin{array}{c}13(32.5 \%) \\
\text { II }\end{array}$ & $\begin{array}{c}15(37.5 \%) \\
27(67.5 \%)\end{array}$ & $\mathrm{x} 2=0.22$ & 0.639 \\
\hline $\begin{array}{c}\text { Time of } \\
\text { operation } \\
(\text { min) }\end{array}$ & $60.90 \pm 11.33$ & $62.15 \pm 9.06$ & $\mathrm{t}=-0.545$ & 0.587 \\
$\begin{array}{c}\text { Mean } \pm \text { SD } \\
\text { Range }\end{array}$ & $40-90$ & $50-90$ & & \\
\hline
\end{tabular}

t-Independent Sample t-test; $x 2$ : Chi-square test

Table 1: Demographic data of both groups.

\section{Outcomes:}

The intraoperative fentanyl consumption in group $\mathrm{H}$ was significantly lower $(167.75 \pm 20.6 \mathrm{ug})$ than that of group B (186.25 $\pm 20.57 \mathrm{ug}) ; \mathrm{P}<0.001$.

Also, the total dose of analgesia (pethidine "mg") in 24hrs. was significantly lower in group $\mathrm{H}$ $(55.75 \pm 14.66 \mathrm{mg})$ than that in group $\mathrm{B}(82.50 \pm 36.57 \mathrm{mg})$ with P-value statistically significant $(\mathrm{P}<0.001)$ (Table 2$)$.

\begin{tabular}{|c|c|c|c|}
\hline & $\begin{array}{c}\text { Group B } \\
(\boldsymbol{n}=\mathbf{4 0})\end{array}$ & $\begin{array}{c}\text { Group H } \\
(\boldsymbol{n}=\mathbf{4 0})\end{array}$ & p-value \\
\hline $\begin{array}{c}\text { Intraoperative } \\
\text { fentanyl consumption } \\
\text { (ug) } \\
\text { Mean } \pm \text { SD } \\
\text { Range }\end{array}$ & $\begin{array}{c}186.25 \pm 20.57 \\
140-220\end{array}$ & $\begin{array}{c}167.75 \pm 20.6 \\
125-220\end{array}$ & $<0.001^{*}$ \\
\hline $\begin{array}{c}\text { Total dose of } \\
\text { analgesia in 24 hours } \\
\text { [Pethidine "mg"] } \\
\text { Mean } \pm \text { SD } \\
\text { Range }\end{array}$ & $82.50 \pm 36.57$ & $55.75 \pm 14.66$ & $<0.001^{*}$ \\
& $40-150$ & $30-100$ & \\
\hline
\end{tabular}

**p-value $<0.001 \mathrm{HS}$

Table 2: Comparison between groups according to their intraoperative fentanyl consumption and total dose of analgesia

The numerical Rating Score of pain postoperatively was significantly less in the $\mathrm{H}$ group than in the $\mathrm{B}$ group at $(0,1,2,4,6 \mathrm{~h})$ (table 3$)$. However, there was no significant difference in the mean NRS postoperatively between group B and group $\mathrm{H}$ at 9 , 18 and $24 \mathrm{hr}$ (Table 3 ). 


\begin{tabular}{|c|c|c|c|c|}
\hline NRS & $\begin{array}{c}\text { Group B } \\
(n=40)\end{array}$ & $\begin{array}{c}\text { Group H } \\
(n=40)\end{array}$ & z-test & p-value \\
\hline $\begin{array}{c}\mathbf{0} \mathbf{h r} . \\
\text { Mean } \pm \text { SD } \\
\text { Range }\end{array}$ & $\begin{array}{c}2.83 \pm 0.87 \\
2-5\end{array}$ & $\begin{array}{c}1.98 \pm 0.62 \\
1-3\end{array}$ & 5.019 & $<0.001$ \\
\hline $\begin{array}{c}\mathbf{1} \mathbf{h r} . \\
\text { Mean } \pm \text { SD } \\
\text { Range }\end{array}$ & $\begin{array}{c}3.00 \pm 0.93 \\
2-5\end{array}$ & $\begin{array}{c}2.38 \pm 0.67 \\
1-4\end{array}$ & 3.444 & 0.002 \\
\hline $\begin{array}{c}\text { 2hrs. } \\
\text { Mean } \pm \text { SD } \\
\text { Range }\end{array}$ & $\begin{array}{c}3.38 \pm 0.84 \\
2-5\end{array}$ & $\begin{array}{c}2.70 \pm 0.82 \\
1-5\end{array}$ & 3.636 & $<0.001$ \\
\hline $\begin{array}{c}\text { 4hrs. } \\
\text { Mean } \pm \text { SD } \\
\text { Range }\end{array}$ & $\begin{array}{c}3.23 \pm 0.77 \\
2-5\end{array}$ & $\begin{array}{c}2.45 \pm 0.64 \\
2-4\end{array}$ & 4.909 & $<0.001$ \\
\hline $\begin{array}{c}\text { 6hrs. } \\
\text { Mean } \pm \text { SD } \\
\text { Range }\end{array}$ & $\begin{array}{c}3.48 \pm 0.93 \\
2-6\end{array}$ & $\begin{array}{c}2.95 \pm 0.88 \\
1-5\end{array}$ & 2.595 & 0.011 \\
\hline $\begin{array}{c}\text { 9hrs. } \\
\text { Mean } \pm \text { SD } \\
\text { Range }\end{array}$ & $\begin{array}{c}4.53 \pm 0.88 \\
3-6\end{array}$ & $\begin{array}{c}4.23 \pm 0.92 \\
2-6\end{array}$ & 1.493 & 0.139 \\
\hline $\begin{array}{c}\text { 18hrs. } \\
\text { Mean } \pm \text { SD } \\
\text { Range }\end{array}$ & $\begin{array}{c}4.75 \pm 1.16 \\
3-6\end{array}$ & $\begin{array}{c}4.38 \pm 0.82 \\
2-6\end{array}$ & 1.647 & 0.104 \\
\hline $\begin{array}{c}\text { 24hrs. } \\
\text { Mean } \pm \text { SD } \\
\text { Range }\end{array}$ & $\begin{array}{c}4.75 \pm 1.17 \\
3-6\end{array}$ & $\begin{array}{c}4.28 \pm 1.07 \\
3-6\end{array}$ & 1.875 & 0.065 \\
\hline
\end{tabular}

Table 3: Numerical Rating Score of pain in both groups

\section{DISCUSSION}

Despite laparoscopic cholecystectomy is being considered a minimally invasive surgery it produced undesirable pain, and its control is challenging. The cause of pain after LC is multifactorial visceral pain, parietal pain caused by pneumoperitoneum, and incisional pain related to trocar sites ${ }^{9,10}$.

Pain management after LC is a great practical issue to reduce the time of hospital stay. Multimodal analgesia allows earlier ambulation, rehabilitation and reduces the possibility of chronic pain syndromes with a low incidence of complications ${ }^{1}, 11$. Multimodal analgesia with different classes of analgesics (NSAIDs, COX-2 inhibitors, gabapentin) and different analgesic administration sites as (intraperitoneal instillation of local anesthetics, transversus abdominal plain block (TAP), RSB block), supply a superior dynamic pain improvement with decreased opioid analgesia associated side effects ${ }^{1}, 12$

Bilateral posterior RSB is used for postoperative pain control, including laparoscopy, umbilical hernia, pediatric, and gynecological surgery. It provides dense and predictable analgesia over the central area of the ventral abdominal wall from the xiphisternum to the symphysis pubis ${ }^{13}$.

Recently many studies have searched the effect of adding hyaluronidase to the different local anesthetic mixtures as an adjuvant in some regional blocks.
The current study aimed to evaluate the effect of adding hyaluronidase to bupivacaine in RSB in patients undergoing LC regarding intraoperative fentanyl consumption and postoperative pain.

The current study has demonstrated the efficacy of adding hyaluronidase to bupivacaine in RSB that significantly lower intraoperative fentanyl consumption in group $\mathrm{H}$ than group $\mathrm{B}$ (167.75 \pm 20.6 and $186.25 \pm 20.57 \mathrm{ug})$ respectively. In a study done by Ibrahim et al. ${ }^{13}$, the authors reported that the mean intraoperative fentanyl dose was (19.23 $\pm 4.96 \mathrm{ug}),(15.28 \pm 2.75 \mathrm{ug})$ in the control group, and posterior rectus sheath block (PRSB) respectively $(\mathrm{P}<0.001)^{11}$.

Kasem \& AbdelKader have reported no statistically significant difference between the $\mathrm{R}$ group (RSB) and the L (local infiltration) group concerning the total amount of fentanyl consumption intraoperatively $(168 \pm 28$ and $174 \pm 36 \mu \mathrm{g}$, respectively) ${ }^{14}$. the design of the study done by Kasem \& AbdelKader is different. They used local anesthetic infiltration in the control group. This may explain the absence of a difference in both groups.

Hyaluronidase is a mucolytic enzyme that acts on the mucopolysaccharide hyaluronic acid and has been considered as a spreading factor. It was first utilized as an adjuvant to local anesthetics in ocular regional blocks where it hastens the onset block and improves the efficacy of anesthesia ${ }^{15}$.

In this study, we found that adding hyaluronidase to bupivacaine in RSB significantly reduced the degree of postoperative pain post $\mathrm{LC}$ as shown by lower pain scores (NRS), in the group (H) at $0 \mathrm{hr} .1 \mathrm{hr} 2 \mathrm{hr}$. $4 \mathrm{hr}$ and $6 \mathrm{hrs}$ postoperatively than group (B) and also there was a reduction in postoperative 24 -h pethidine consumption in group $\mathrm{H}$ than group B $(55.75 \pm 14.66$ VS $82.50 \pm 36.57 \mathrm{mg}$ ). RSB has been assessed previously after laparoscopic cholecystectomy for postoperative analgesia. Jeong et al. has demonstrated the efficacy of US-guided RSB as preemptive analgesia by the decrease in total amount of analgesic consumption at $24 \mathrm{~h}$ post-surgery also, there was a decrease in postoperative pain which has been measured by (NRS) at $0,1,2,6,9,18$, and $24 \mathrm{~h}$ after surgery ${ }^{1}$.

In a match with this finding Gupta et al. assessed Pre-emptive administration of rectus sheath block group (R) compared to intraperitoneal instillation of $0.25 \%$ ropivacaine group (I) by pain score and total postoperative analgesia, the result has shown that RSB is effective in providing better postoperative analgesia as mean visual analogue score (VAS) score was statistically significant higher in the control group $(\mathrm{C})$ in comparison to $(\mathrm{I})$ and $(\mathrm{R})$ Groups, while it was similar between Group I and Group R (Group $\mathrm{C}>$ Group $\mathrm{I} \approx$ Group $\mathrm{R}$ ). In the first 6 hours, the total dose of rescue analgesia required in Group C (28) was substantially greater than in Group I (4) and Group R (0), p<0.001. ${ }^{16}$

Many studies demonstrate the effectiveness of adding hyaluronidase as an adjuvant to different blocks. The study of Bhaskar et al. has found a significant decrease in NRS at coughing by adding hyaluronidase to TAP and may be due to the improved analgesia quality ${ }^{17}$. Also, the study of 
Chaudhari \& Chaudhari has shown that use of hyaluronidase as an adjuvant to local anesthetics in inguinal hernia block operations was effective by improving and prolonging the time of pain killer. Pain scores were statistically significantly lower in the hyaluronidase group at 2 and $6 \mathrm{~h}$ postoperatively also, with a lower number of patients who requiring intraoperative analgesics ${ }^{18}$.

In a match with Johnson \& O'Connor that has shown effective and prolonged analgesia by adding hyaluronidase to local anesthetic (LA) in subcostal TAP for (LC) by improving the spread of the (LA). The assessment of pain by VAS at four hours intervals postoperatively until discharge in the following morning. VAS scores were $0 / 10$ at all measurements until discharge ${ }^{19}$.

\section{CONCLUSION}

preoperative RSB with adding hyaluronidase to bupivacaine has reduced the analgesic requirements during the intraoperative and the first $24 \mathrm{~h}$ postoperatively, in comparison to the preoperative RSB without adding hyaluronidase in patients undergoing LC.

\section{REFERENCES}

1. Jeong H-W, Kim CS, Choi KT, Jeong S-M, Kim D$\mathrm{H}$, Lee J-H. Preoperative versus Postoperative Rectus Sheath Block for Acute Postoperative Pain Relief after Laparoscopic Cholecystectomy: A Randomized Controlled Study. J Clin Med. 2019;8(7):1018. doi:10.3390/jcm8071018

2. Tor IH, Çelik EC, Aydın ME. Analgesic effect of combined transversus abdominis plane block and rectus sheath block in laparoscopic cholecystectomy: prospective randomized study. Ain-Shams $J$ Anesthesiol. 2020;12(1):58. doi:10.1186/s42077-02000108-4

3. Mitra S, Khandelwal P, Roberts K, Kumar S, Vadivelu N. Pain Relief in Laparoscopic Cholecystectomy-A Review of the Current Options. Pain Pract. 2012;12(6):485-96. doi:10.1111/j.15332500.2011.00513.x

4. Shokri H. The efficacy of rectus sheath block for pain management following laparoscopic orchiopexy surgery. Ain-Shams J Anaesthesiol. 2018;10(1):21923. doi:10.4103/1687-7934.238459

5. Warman P, Conn D, Nicholls B, Wilkinson D. Rectus sheath block. In: Warman P, Conn D, Nicholls B, Wilkinson D, eds. Regional Anaesthesia, Stimulation, and Ultrasound Techniques. Oxford University Press; 2014:381-388. doi:10.1093/med/9780199559848.003.0034

6. Quek K, Phua D. Bilateral rectus sheath blocks as the single anaesthetic technique for an open infraumbilical hernia repair. Singapore Med J. 2014;55(03):39-41. doi:10.11622/smedj.2014042

7. Ibrahim, M., El Shamaa, H., \& Ads, E. (2016). Efficacy of combined ultrasound guided anterior and posterior rectus sheath block for postoperative analgesia following umbilical hernia repair: Randomized, controlled trial. Egyptian Journal of Anaesthesia, 32(4), 519526.https://doi.org/10.1016/j.egja.2016.10.009
8. Marshall SI and Chung F(1999): Discharge criteria and complications after ambulatory surgery , Anesthesia and analgesia,88(3),508-517.

9. Liang M, Chen Y, Zhu W, Zhou D. Efficacy and safety of different doses of ropivacaine for laparoscopy-assisted infiltration analgesia in patients undergoing laparoscopic cholecystectomy. Medicine (Baltimore). doi:10.1097/MD.0000000000022540

10. Kim JS, Choi JB, Lee SY, et al. Pain related to robotic cholecystectomy with lower abdominal ports. Medicine (Baltimore). 2016;95(31):e4445. doi:10.1097/MD.0000000000004445

11. Batley SE, Prasad V, Vasdev N, Mohan-S G. PostOperative Pain Management in Patients Undergoing Robotic Urological Surgery. Curr Urol. 2016;9(1):511. doi: $10.1159 / 000442843$

12. Jin F, Li Z, Tan W, Ma H, Li X, Lu H. Preoperative versus postoperative ultrasound-guided rectus sheath block for improving pain, sleep quality and cytokine levels in patients with open midline incisions undergoing transabdominal gynecological surgery: a randomized-controlled trial. BMC Anesthesiol. 2018;18(1):19. doi:10.1186/s12871-018-0485-9

13. Ibrahim M, El Shamaa H, Ads E. Efficacy of combined ultrasound guided anterior and posterior rectus sheath block for postoperative analgesia following umbilical hernia repair: Randomized, controlled trial. Egypt J Anaesth. 2016;32(4):519-26. doi:10.1016/j.egja.2016.10.009

14. Kasem A, AbdelKader A. Ultrasound-guided rectus sheath block versus local infiltration in management of pain after single-incision laparoscopic cholecystectomy. Ain-Shams J Anaesthesiol. 2015;8(1):100. doi:10.4103/1687-7934.153950

15. Elsayed S, Ahmed F, Khalifa O. Hyaluronidase versus adrenaline as an adjuvant to bupivacaine in ultrasound-guided supraclavicular brachial plexus block for upper limb surgeries. Res Opin Anesth Intensive Care. 2019;6(2):206. doi:10.4103/roaic.roaic_121_18

16. Gupta M, Naithani U, Singariya G, Gupta S. Comparison of $0.25 \%$ Ropivacaine for Intraperitoneal Instillation v/s Rectus Sheath Block for Postoperative Pain Relief Following Laparoscopic Cholecystectomy: A Prospective Study. J Clin Diagn Res. 2016;10(8):UC10-5. doi:10.7860/JCDR/2016/18845.8309

17. Bala Bhaskar S, Shetty P, Chand N K, D S. Abstract PR482. Anesth Analg. 2016;123(3):611. doi:10.1213/01.ane.0000492868.17327.e3

18. Chaudhari A, Chaudhari V. Local anesthetic agents along with hyaluronidase for inguinal hernia block provides excellent analgesia: a double blind study. Int J Basic Clin Pharmacol. 2013;2(4):466. doi:10.5455/2319-2003.ijbcp20130822

19. Johnson MZ, O'Connor TC. Excellent postoperative analgesia with the addition of hyaluronidase to lignocaine for subcostal TAP block used in conjunction with systemic analgesia for laparoscopic cholecystectomy. Case Reports. 2014;2014(feb06 2):bcr2013202911-bcr2013202911. doi:10.1136/bcr2013-202911 